\title{
Coaching for recovery: a quality improvement project in mental healthcare
}

\author{
Anna Burhouse, Madeleine Rowland, Heather Marie Niman, Daisy Abraham, Elizabeth Collins, Helen Matthews, Joanna Denney, Howard \\ Ryland \\ 2gether NHS Foundation Trust
}

\begin{abstract}
Approximately one in four adults in the UK will experience a mental health difficulty at some point in their life. This figure is approximately 400 million people worldwide.[1] Depression alone is currently estimated to cost the UK 1.7\% of GDP and is one of the largest causes of ill health in the world.[2] For conditions like psychosis, evidence tells us that people have poorer quality of life outcomes, are more likely to die early, become obese, smoke, be unemployed, and have long term physical conditions than average.[3] People's social situation is also likely to be more complex, with housing needs, social isolation, stigma, and poverty.[4] All of these factors can make it hard for a person with a long-term mental health condition, or those supporting them, to hold onto a sense of hope that positive change is possible or that "recovery" towards a life that holds optimum meaning to them is achievable.
\end{abstract}

An innovative "pop up" Recovery College model was co-produced, delivered, and evaluated by a team of people with lived experience of mental health difficulties, known as peer trainers. The Recovery College offered courses containing the best evidence-based knowledge about recovery in mental health, self-care and self-management. Each learning session included theory, personal testament from peer trainers, and volunteers and demonstrations of practical self-care skills and techniques.

The courses were open to people experiencing mental health difficulties, their families, friends, and professionals. After the college course finished each student was offered up to three individual coaching sessions to help support putting the lessons learnt from the college into practice.

The project aimed to test whether this innovative educational and coaching model could offer hope, knowledge and practical skills in selfmanagement to support resilience and recovery. The project was underpinned by quality improvement methodologies to develop, deliver, and refine the model.

\section{Problem}

In the UK, mainstream primary care and mental health services delivered by the NHS are providing treatments for 1.6 million people.[5] Approximately 25 to $50 \%$ of all visits to a GP practice involve a mental health component, with GPs treating $90 \%$ of all common mental health difficulties.[6] Adults in the UK are currently accessing NHS specialist mental health services for the treatment and management of severe and enduring mental health conditions, such as psychosis, depression, anxiety, eating disorders, personality disorder, and bi-polar disorder.

- Schizophrenia is experienced by one in every 100 people [7]

- One in every 100 people in the UK experiences other forms of psychosis such as bipolar disorder [8]

- The management of psychosis in specialist NHS mental health services accounts for approximately $33 \%$ of all mental health payment by results activity, with approximately $10.4 \%$ of all care being for people with stable psychosis who arguably could be better served by self-empowered management, community support, and primary care than specialist mental health services [9]

These statistics tell us about the demand for services, but they do not tell us the "human story" of the current NHS mental health system. The range of treatment given for severe and enduring mental illness in the UK predominately centres on the administration of pharmacological and talking therapies in primary care, with access to specialist community mental health teams, hospital beds, and crisis care in times of acute need. Many people with lived experience of mental illness feel that mainstream NHS services are very limited in what they offer and do not reliably address the impact of living with a long term mental health condition, or proactively address associated health and social inequalities.[10]

Some report that they were inadequately supported to adjust to their diagnosis, understand how to live well with mental illness or find adequate help to understand how to make positive changes to their lifestyle to prevent relapse or worsening of their condition.[11] In addition, carers often feel unsupported by health professionals and describe feeling that they are not fully included in care or adequately informed about their relative's mental illness.[12] Getting practical support when you feel very unwell can also be problematic as health, social care, housing, and employment systems are rarely fully integrated and can be confusing to access. Mental health stigma is also an issue and can prevent people from both seeking and gaining support. 


\section{Background}

Approximately one in four adults will experience some kind of mental illness in their lifetime. The World Health Organization states that unipolar depressive disorders will become the top major cause group of the total disease burden in the world by 2030, moving from being the third largest category in the world in 2004.[1] The Department of Health reports that mental illness represents up to $23 \%$ of the total burden of ill health in the UK and is the largest single cause of disability.[13] The number of adults experiencing common mental health disorders in England has risen steadily from $15.5 \%$ in 1993 to $17.6 \%$ in 2007.[5]

The King's Fund [14] projects a 14\% increase in the number of people with mental health problems between 2007 and 2026. Hence by 2026, projected mental health service costs, including real changes in prices, will rise from 1.7\% GDP (£22.5 billion) to $3.5 \%$ GDP ( $£ 47.5$ billion). When all costs associated with mental illness are taken into consideration, including the economic impact of lost employment, current costs are equivalent to $3.6 \%$ of GDP and are predicted to rise to $6.6 \%$ by 2026 .

Many mental health conditions can often be successfully treated, however some severe and enduring mental health conditions are unfortunately associated with poor life outcomes and health inequalities. For example, people diagnosed with psychosis in the UK are more likely to die prematurely, be unemployed, smoke, and have long-term physical conditions than the average British citizen.[3] The social situation of people with enduring mental health conditions, such as psychosis, is also more likely to be complex, with a greater risk of unmet housing needs, social isolation, stigmatisation, and poverty.[4]

Throughout most mental health Trusts within the NHS, the majority of routine outpatient work for severe and enduring mental illness (i.e. for those not in crisis or at high risk) is delivered via community appointments. These typically occur once or twice a month and vary from ten minutes, to give an injectable medication, to up to an hour for a routine therapeutic or care planning session. The rest of the time, people with enduring mental illness rely on their own ability to manage their care, and/or on the support and help of friends, family, carers, GPs or voluntary sector providers. There is therefore a strong imperative to develop effective mental health promotion, physical health prevention and self-management strategies for people who are newly diagnosed and those with chronic or longterm mental health issues. The challenge is to develop innovative services that aim to increase self-management of the mental health condition and to address unemployment, poor physical health and other quality of life issues.

In physical health long-term conditions, such as diabetes, there has been a significant rise in the role of the 'Expert Patient' to help teach self-management techniques. In addition, in the treatment of cancer there is an increasing emphasis on 'survivorship'[15] and a growing recognition that more holistic help is required to support the longterm physical, psychological, social and economic after effects of the disease. In 2011, the King's Fund identified the need to commission active support for self-management as the most significant priority for transforming the healthcare system in England.[16] This is seen as important for both physical and mental health conditions, particularly as there is such a strong correlation between the two.

People with long-term mental health conditions are increasingly looking for alternatives to pharmacological management alone and seeking out psychological, emotional, spiritual and educational perspectives to better understand and manage their conditions. Specialist NHS adult mental health services are not currently designed or resourced for the volume of demand that is emerging in the area of self-management.

The concept of 'Recovery' in mental health is gaining traction in mainstream NHS mental health services in the UK. It is commonly used to describe an individual's way of living a meaningful life beyond mental illness and how they conceptualise their own experience of mental illness. It often has a very personal meaning for each individual and so can be hard to define collectively. ImROC (Implementing Recovery through Organisational Change) describe it as 'A personal journey of discovery that involves making sense of and finding meaning in what has happened, becoming an expert in your own self-care, building a new sense of self and purpose and discovering your own resourcefulness. Users of mental health services have identified three key principles:

- The continuing presence of hope that it is possible to pursue one's personal goals and ambitions

- The need to maintain a sense of control over one's life and one's symptoms

- And the importance of having the opportunity to build a life beyond illness.'[17]

'Recovery' is also becoming a model for change for people who want a more holistic approach to their long term health condition management or 'survivorship' than is consistently offered in mainstream NHS mental healthcare services at present.

The concept of 'Recovery' is also having an impact on mental health professionals. Those that adopt 'Recovery' as an underpinning approach to their work often see significant changes in their own clinical practice and personal attitudes, including an active wish to change the power balance between 'doctor/professional' and 'patient' to one that is more equitable. There is also a growing focus on how to enhance recovery through organisational change as outlined in the Sainsbury Centre for Mental Health Policy Guidance 'Implementing Recovery: A Methodology for Organisational Change'[18] and championed by organisations such as ImROC (Implementing Recovery through Organisational Change).

On this matter, Jacobson \& Greenley (2001 p.483) state that "Recovery is variously described as "Something that individuals experience, that services promote, and that systems facilitate."[19] At an individual level, there is no consensus about a single definition of recovery, as each person's definition will be unique. 
Already the Recovery College project has collected hundreds of different definitions of recovery. Whilst each definition was unique, commonly recurring themes included:

- The ability to be seen as a 'whole person' not 'just as a mental health patient'

- To live a meaningful and productive life

- To feel hopeful about the future and able to seek out opportunities for growth, progression and happiness

- To have a greater sense of control about how to deal with the underlying illness

- To feel connected with others and be seen as having worth by society

Recovery theory also embodies the concept of collaboration and "co-production". In healthcare, co-production is based on the sharing of information and opinions between service users and providers in order to support shared decision-making processes and health processes.[20] It builds on the assumption that both parties have an important role to play in the co-creation of ideas, services and products as they contribute diverse perspectives and bring different knowledge and expertise.[21] The co-production of mental health services by people with lived experience of mental illness is cited by the Department of Health and NHS England as best practice.[22]

Recovery is often described as a counterpoint philosophy of care to the traditional 'medical model' of mental health delivery, which some feel focuses too much on an individual's diseases and symptoms rather than on a more holistic person centred approach to care. These frustrations with the medical model have been fuelled by the introduction of standardised disease classification systems such as the Diagnostic and Statistical Manual of Mental Disorders,[23] where critics argue that common human experiences, such as reactions to loss through bereavement for example, have become over-medicalised.

The medical and recovery models of care need not be mutually exclusive and can be complementary. Many mental health/social care professionals have successfully adopted a recovery approach alongside traditional practice. Many see this integrated approach as being at the core of person-centred care. Other professionals reject this philosophy, denying that 'recovery' is possible. They focus on a biological and genetic approach to care and feel that talking of 'hope' of recovery is misleading, a myth or even dangerous.[24]

Despite a growing evidence base for recovery,[25, 26, 27, 28, 34, 35 ] the provision of 'recovery orientated' services in the NHS is highly variable at present. This can be because of differences in professional practice and belief. It can also be because of the way services are commissioned. Even where NHS Trusts that have adopted the recovery philosophy at an organisational level, there is no guarantee that members of staff are trained in this approach and apply it to their practice. This is because to practice in a systematic recovery-orientated way also relies on the establishment of an organisational 'Recovery' culture [17] with systems that support an integrated approach to health, social care, housing, employment, education and occupation etc. Commissioners have a key role to play in this area, to support 'parity of esteem' with physical health as outlined in 'No Health without Mental Health'.[13]

A recovery college runs educational courses designed and led by people with lived experience of mental health conditions. The aim is not to 'cure' people of their condition, but to support people with mental health conditions, some of which might be life-long, to undertake a personal transformational journey of 'recovery' towards an increased sense of hope and wellbeing, "involving the growth of new meaning and purpose beyond the effects of mental illness".[29]

Resnick et al [30] believe the key elements of recovery for people with long-term mental illness are:

- Satisfaction with life

- Hope and optimism

- A sense of empowerment

- Knowledge about mental illness, well-being, skills and services

Meaningful connection with others and human rights are crucial too.[19] The recovery philosophy also recognises the important role that families, friends, carers and the local community play to support social inclusion.

The idea of the Recovery College is to support students to learn a mixture of practical 'recovery' skills and tools through:

- Peer led education seminars about mental health conditions and self-management techniques

- The sharing of recovery stories to promote hope, share a sense of inclusion and overcome perceived alienation

- Promoting a shared decision making framework with professionals, helping to improve the power balance, have honest conversations about risk and increase self confidence in creating and using a personalised 'recovery plan'

- The reduction of feelings of isolation through social inclusion

- Sharing information about local community resources

- Promoting a strengths based model of well-being rather than focusing on culturally defined 'deficits'

The Recovery College helps people to understand more about their diagnosis in order to make informed choices about treatment is central to National Institute for Health and Care Excellence (NICE) clinical and service user experience guidelines.[32] Knowledge about health conditions is crucial in order to participate in shared decision-making.[33] In mental healthcare education can also help 
to improve decisions about risk management and how to keep well.

The South West London Recovery College (SWLRC) was the first Recovery College to open in the UK in September 2010. They have undertaken longitudinal studies that demonstrated a statistically significant reduction in mental health service usage for graduates of the Recovery College at twelve months post-course.[34]

A review of recovery colleges in the UK has shown positive health outcomes for those involved, particularly in the ability to promote hope about the future and increase self-management.[35] It has also demonstrated a significant reduction in the need for secondary mental health services following attendance at a recovery college.[36] Further research and economic modelling has yet to be undertaken on the impact of the Recovery College model both in relation to the use of secondary mental health services and also to describe the impact of changes in lifestyle on physical health outcomes. It could be that learning skills for recovery and resilience at a Recovery College aids students to introduce preventative measures for behaviours, such as self-harm, therefore reducing the need for visits to Accident and Emergency departments etc. Learning about protective factors, in the case of eating disorder patients, could establish more positive lifestyle choices and thus reduce the risk of long-term health problems, such as poor bone health/osteoporosis or digestive problems.

The Recovery College represents a 'disruptive innovation' and paradigm shift to complement and influence traditional mental healthcare [31] because it disseminates knowledge about mental health conditions across a wider population, shares information and resources on self-management techniques and inspires change through peer support.

\section{Baseline measurement}

Fifty students from three Recovery College courses undertook a precourse questionnaire that asked them to self-rate against a series of statements designed to capture their sense of hope and recovery. We also asked students to complete the Manhattan Recovery Measure(36) in order to track their recovery journey over the length of the course. This measure combined some standard questions that all students answered along with four questions they designed for themselves that were unique to their own recovery journey.

In addition to this we encouraged students to keep a written account of their experience of the course in a Recovery Journal and embedded opportunities for qualitative feedback throughout the course.

With the students' permission, a basic information data set was collected on registration:

- Demographics; age, ethnicity etc (collected by Adult Education)

- Mental health diagnosis (if appropriate/known)

- Summary of treatment (if appropriate/known)
- Mental health payment by results cluster (if appropriate/known)

- Care Programme Approach status (if appropriate/known)

- Contact with health care services - length of contact with services, frequency and intensity pre-six months, pre-12 months (if appropriate/known)

- Housing status

- Employment, occupation, or education status.

\section{Design}

The original design was to develop two "pop up" Recovery Colleges in Gloucestershire and Herefordshire open to people with mental health problems, their families, friends and health and social care professionals. Everyone who enrolled in the college became a 'student' with equal status and access to resources. No differentiation was made between service users, carers or staff and each person was equally appreciated for their individual contribution. The courses were run in educational rather than health settings and everyone was enrolled as an adult learner with the local adult education service.

We co-designed the Recovery College with people with lived experience of mental health. We aimed to:

- Design the Recovery College concept for our locality

- Agree on the course materials

- Plan the course structure

- Deliver three recovery college courses for up to 50 people

- Agree on operational project management, governance and financial structures

- Develop a website and communications strategy

- Design a range of evaluation methods

- Develop peer trainer, volunteer and coach job descriptions, recruit and then deliver training to these recruits

- Work in partnership with key stakeholders

- Underpin our approach to this work by using quality improvement science

- Write up and disseminate our work together.

\section{Strategy}

The underpinning service improvement methodologies used in the project were experience-based co-design [37] and Model for 
Improvement [38] PDSA (Plan, Do Study, Act) cycles. We used these methods extensively to develop the course content and see which of the recovery college formats worked best. We also used a micro-systems approach [39] to coach peer trainers and the recovery college team in quality improvement methodologies.

\section{Experience based co-design for recovery college concept}

We planned to develop a version of the South West London and Nottingham Recovery colleges that was suitable for the largely rural counties of Gloucestershire and Herefordshire. Both the London and Nottingham models had a permanent physical base for the Recovery College suitable for their urban settings. We felt that this model would not work as well over a large rural geographical area. Instead we designed temporary 'pop up' Recovery Colleges that made the best use of local educational resources like local colleges and adult education centres.

After visiting the South West London Recovery College and talking extensively to the peer trainers we recognised that in designing the Recovery Colleges in this way we would be missing out on the informal support that having a permanent base could offer, so we redesigned the plan to include:

- Five "taster days" where people could come along and see if the Recovery College course was for them

- A café style space for socialising over lunch as an integral design element of the course

- The option for students to have up to three personal coaching sessions at the end of the college course to help provide ongoing motivation for change

- A follow up student designed "Recovery Space Day" to allow students to have further sessions on practical and creative skills they had tried on the course but wanted deeper learning/experience. It was also used as a place where people could also experiment with becoming a peer trainer by leading a workshop on a skill they had

- A graduation event several months later to offer people a chance to celebrate their success together

- The provision of self-management support workbooks at the end of the course for those that wanted to continue the practice

- The use of volunteers for classroom support, travel and reasonable adjustments.

1. Plan, do, study, act cycles for course design:

The course was co-produced and delivered by a team of people with lived experience of mental health difficulties, known as peer trainers. The peer trainers worked with a range of stakeholders from the NHS, business and voluntary sectors to develop a set of course materials. Over the course of three PDSA cycles the course materials, educational exercises and self-management strategies were tested and refined. The course materials were designed to help people build on their existing skills, explore their possibilities and aspirations and gain confidence and knowledge in order to make positive life changes. The courses contained the best evidence based knowledge about recovery in mental health and selfcare. Each learning session included theoretical learning, personal testament from the peer trainers and volunteers and demonstrations of practical self-management skills and techniques.

We trialled the use of personal coaches, local artists, mindfulness trainers, library support workers, educational and vocation and employment specialists to offer imaginative ways of developing varied recovery skills. Students then chose a range of activities for additional 'Recovery Space Days', this included learning about the use of gratitude diaries, using art for recovery, drama skills, relaxation sessions and writing groups. Several students took on the role of peer trainers on these days and shared their expertise.

Outside of the course each student was offered up to three individual coaching sessions to support the achievement of their self-set goals and each student was given a set of self-help workbooks to continue the work after the course had completed. Both during and at the end of each course we invited students to help us think about how to improve the next one. We kept a log of suggestions to test and measure.

\section{PDSA cycles for course structure:}

We trialled four types of course design; an intensive course for four full days, a three hour morning course plus lunch for eight weeks, a three hour afternoon course plus lunch for eight weeks and one day 'Recovery Space Days' full of interactive activities. We collected data from each cycle to see if there was any difference in the outcome measures or qualitative feedback after delivering in different ways.

\section{Results}

An independent evaluation was undertaken by an external contractor at the end of the Recovery College project.

Evaluation was undertaken using:

\section{- Pre and post course questionnaires \\ - Self reported outcome measures}

- Post course: Independently facilitated focus group evaluation approach with peer trainers, coaches, partner agencies and the project team about the PDSA cycles and lesson learnt from the project

- Post course: Independently facilitated focus group evaluation with students, which used a phenomenological approach to understanding the experience of participating in the College and what benefits were derived.

Pre and post questionnaire 
Students from the three Recovery College courses undertook a precourse questionnaire that asked them to self-rate against a series of statements designed to capture their sense of hope and recovery and self-management skills. The aggregated results of the three recovery colleges' pre and post-questionnaires showed that $94 \%$ of students felt more hopeful after attending the course and $91 \%$ of students felt they had greater knowledge and greater selfawareness. Many other improvements in a range of selfmanagement skills were seen too; in self confidence, self control, daily routines and understanding of others (see graph 1 ).

Pre and post outcome measures

Pre and post outcome measures, using the also showed that everyone in the college had made improvements in understanding of their illness, improved knowledge about recovery, showed greater self-management skills. As a core part of these measures we asked students to define at least two personal recovery goals and agree how they would measure success. The personally defined recovery goals and measures were individual to each student but included issues like:

"Reduce the number of times I self harm"

"Go out of the house every day"

"Take my medication regularly"

"Stick to my wellness recovery action plan"

"Try and talk to someone if I feel depressed"

"Exercise three times a week"

"Ignore the critical voices in my head"

"Start a new hobby"

"Keep applying for jobs until I am successful"

"Finish my doctorate"

"Make progress towards going back to work as an accountant"

$100 \%$ of students made progress against their own recovery goals, but students on the six week course did better than those on the intensive course, suggesting that this way of delivering the course is more effective.

\section{Focus groups}

In addition, qualitative data about the project was collected via post course focus groups held after the recovery college courses had completed. All students were invited to attend and many brought the Recovery Journal they had kept throughout the course with them for reference. The independent contractor worked with the peer trainers to develop a set of open questions to elicit the students experience of the college and what impact if any they thought it had made on them as an individual.

The qualitative data from the focus groups was thematically analysed to identify, analyse and report patterns using NVivo qualitative data analysis (QDA) computer software. This data confirmed the self reported outcome measures above, showing that many of the students perceived that they had undergone significant personal transformation as a result of being on the course. Key themes included:

\section{- Personal transformation}

- An greater ability to contemplate the future

- A sense of hope and excitement about what might be possible

- A sense of empowerment

- A decrease in the amount of shame felt about their illness

- An increase in knowledge about their own and other's illnesses

- A sense of belonging and not being alone

- Gratitude to the College and in particular to the peer trainers for providing a new way of thinking about their illness

- Finding the Recovery College a safe place to learn and contribute.

"A huge part of the course was the environment created by [the peer trainers]....a completely safe learning space where everyone felt they could contribute" (Gloucestershire student 2013).

"I felt safe in myself and in my surroundings. I haven't felt that in a long time" (Herefordshire student, 2013)

To give a flavour of the transformative nature of this project we have permission to share the following deeply personal quote from a student:

"I see recovery as a journey now, one fraught with obstacles and little miracles. Recently I attended one of the pilot Shine Recovery Colleges. I consider myself very fortunate to have had the opportunity to attend the college. I gained a lot and lost a few things along that eight week journey. The most precious thing I took away with me was a sense of hope. Tiny pinpoints of light woven into the fabric of my experience, for which I am extremely grateful. The most fascinating aspect of the course was that although we received a large amount of very helpful information on all aspects of recovery, it was the experience of participating actively in the course that for me brought about the greatest change and the most in depth learning concerning my own recovery. For the first time in my life not only am I accepted just as I am, I'm being told that mental illness needn't keep me from living a fulfilling and rewarding life and even better this attitude was being backed up with instances of people who really are living with their mental illness and are staying well. 
Personally my struggle with mental health problems stretches over a period of fourteen years and until I experienced the Shine Recovery Colleges, I had little hope of a serious shot at a semblance of a future and no solid concept of what recovery really was.

l'd pretty much been stumbling around in the dark and the Shine Recovery College helped literally to shine enough light into that darkness to show me the beginning of a way forward. My inner life changed dramatically. I could think past 'today' without being paralysed by fear. I could think about what I might actually want to do with my life in a positive way for a change, rather than only in a destructive and negatively hopeless way. Some of the changes in me were more subtle. I found a sense of fun during the college, of optimism and mutual support and respect that helped me feel safe and able to contribute to the discussions. I found a place and a group of people that I could trust and be trusted in reverse. A feeling of belonging sums it up really, another gift.

I take with me that precious sprinkling of hope. With that on my side I'm in a much stronger position to deal with whatever life throws at me. I'm on a journey, one of recovery, of living, and of believing that life holds something more for me than just surviving.

(Recovery College graduate Autumn 2013).

Hope meant a lot to those students working in mental health settings too: "Without a belief in hope we would not come into work in the morning, we would not pick ourselves up after disappointments and we would never be able to work in an area that is as difficult as mental health". (Recovery College graduate, January 2014).

Ludema, Wilmot, and Srivasta state:

"When people hope, their stance is not only that reality is open, but also that it is continually becoming. Rather than trying to concretize and force the realisation of a preconceived future, by hoping people prepare the way for possible futures to emerge. In this sense, hoping can be seen as a deeply creative process".[40]

Throughout the project we were keen to have students contribute to the ongoing quality improvement of the course. We used Experience Based Co-Design and Appreciative Inquiry [41] as our underpinning methodologies to ensure the dialogue about improvement was a core part of the Recovery College experience. We used conversations, case vignettes and video to capture what we could do more or less of and tested changes that resulted from these discussions as a core part of our PDSA and co-production approach. In addition many students also offered their thoughts about the Recovery College process via recovery journals, artwork, poems, letters and films and spontaneously gave us materials that they were happy for us to share to spread the message about the College for our course materials, leaflets, website and presentations.

Since completing the pilot we have trained approximately 300 students (July 2015) and our data base continues to show that the course is making a difference to individuals. Interestingly, this larger data set demonstrates a reduction in use of secondary care mental health services and an increase in the numbers of students returning to work, education or occupation compared with peers. We are therefore starting to collaborate with other Recovery Colleges to analyse the data to see if this work is having a socioeconomic impact alongside the tangible gains it appears to offer individuals.

See supplementary file: ds4026.pptx - "Outcome Measures Recovery College"

\section{Lessons and limitations}

We managed to deliver more than we had originally planned because we received additional support from a range of key stakeholders. The evaluation shows the importance of the coproduction ethos we adopted where peer trainers, students, volunteers and partner organisations all contributed to make the Recovery College experience vibrant and memorable. The success of this project was also founded on the advice, support and generosity of the partner organisations we worked with; Gloucestershire Adult Education Services, Herefordshire Adult Education Services, Herefordshire MIND, Artshape and Family Lives who believed in the model and worked closely with us to deliver this service in an innovative way. Without their help and support we would not have been able to deliver this project in such a creative way.

The Recovery College model for change highlights the powerful impact that hearing personal stories of recovery can have on others. Combining a sense of hope that change is possible alongside an educational framework that teaches people new skills, delivers greater self-awareness and an understanding of mental illness appears to be a powerful vehicle for recovery.

The critical success factors for this project were:

- The students willingness to engage with this model and share their own experiences

- The willingness of people with lived experience of long term mental health conditions to stand up and publicly share their stories of resilience and recovery

- The high quality and experience of the peer trainers and their ability to adapt the course materials to meet the group's needs

- The peer support students offered each other

- The inter-agency networking and support

- The commitment and energy of the volunteers, staff and coaches (which went way beyond what you might expect from discretionary effort)

- Siting the Recovery College in educational settings 


\section{- Excellent communications support}

- The provision of café style facilities for people to sit, eat together chat and build friendships

- The use of artists and skill based practitioners

- The advice, encouragement and support we received from peer trainers at South West ?London Recovery College and the expertise from IMROC

- The support from the executive team and managers in 2gether NHS Foundation Trust to release staff for this project. Whilst we could provide money for back-fill, replacing people for short-term work was difficult to organise. This was mainly achieved through goodwill; by kind colleagues offering to help out by doing extra shifts or by moving schedules around. Without this flexibility from colleagues we would not have been able to have such a rich variety of skills to offer in the Recovery Colleges. This model also allowed more staff to be involved than we had originally planned

- The enthusiasm of students who wanted to continue to be involved and to help co-design a wider variety of courses and become peer trainers.

Whilst the majority of feedback we received about the Recovery College was positive we also invited people to help us learn how to continuously improve and in effect invited the student body and teaching faculty to take part in the PDSA cycles about each course. Several themes emerged. These included:

- We need to think more about the hurdles students face to attend the Recovery College. Some of these were practical, like childcare, paying for parking or access to transport. Others were psychological, like not believing you were good enough to go to 'College'. Some were educational, with students needing literacy support or other reasonable adjustments

- The educational range in the group was very wide; several students had literacy issues or specific learning difficulties. Some students had no formal education qualifications whilst others had doctorate or professional qualifications. Coming from the healthcare sector we had not given this issue enough thought in our original design of the courses and materials. We were extremely grateful that students offered each other high levels of peer support both educationally and emotionally and that we had dedicated volunteers who could offer individual students one-to-one support. We were also extremely grateful for the fantastic input from adult education colleagues, who provided us with expertise and technical help. In two of the PDSA trials, adult education colleagues attended the college at lunchtime and their informal presence became a key route for many students to discuss how they mights access mainstream adult education classes. Adult education's continued input into the project as a part of the steering group, is also helping us to address the educational elements of the project

- Many students wanted to go on to do further learning at the end of the Recovery College course, so we need to establish better transitions into mainstream education courses and offer more courses at the Recovery College to aid progression

- Over $80 \%$ of graduates wanted to stay involved and help the college grow. We had not anticipated this and we now have a growing community of volunteers

- We need a clearer framework for developing, training and employing peer trainers and peer workers throughout the Trust and not just in the Recovery College. This has widespread implications for service design, organisational policies, procedures and culture

- The venue and atmosphere of the Recovery College is important and for a rural community it is important to factor in time and costs for people to socialise together

- The course materials and personal testimonies focused too much on psychosis and not enough on depression

- We didn't explain in our literature that attendance at the Recovery College would not affect benefits

- For some people paying for transport, petrol and parking was difficult and made the decision to attend harder

- Some people really missed the Recovery College and the student body when the course ended. This was exacerbated in the PDSA trial of the intensive four day course we attempted. Our learning is that transitions out of the College are as important as how we welcome people in and that we have to work hard to provide structured pathways onto next steps. We have also be working on how to use social media and our website to create a 'virtual community'. One of the three student bodies took a proactive approach to transition, applied for and were granted some local charitable funding and set up an ongoing reading and meeting group, open to all. We supported this 'grass roots' approach by providing facilitation resources

- On reflection it would have been better to have separately evaluated the impact of the college and the coaching, by asking some specific questions about the value of having both, or why some people chose not to take up the offer of coaching

- This project benefited greatly from discretionary effort of staff and volunteers; the impact of which is difficult to model financially

- We ran out of time to engage some of the specialist mental health teams, GPs and other key stakeholders as well as we would have liked. Whilst this had no immediate impact on the delivery of the project, we have identified this as a weakness and feel it will be a key area to address for the sustainability of the project.

One of our greatest self-imposed challenges was to try to provide some longitudinal measurement of change/reduction in use of mainstream specialist mental health services following graduation from the Recovery College. We were not able to achieve this during this pilot PDSA phase because we had to act on the advice of our Trust who felt that this longer term follow up would constitute 
research not service evaluation. This reflects current national thinking and is a specific challenge for longitudinal quality improvement evaluation.

The links to adult education were enormously important in the delivery of the college, particularly when the courses came to an end. In both counties with the support of local adult education services, students were supported into mainstream courses or we were able to work with local providers to design bespoke courses to build on the work of the recovery college. In Gloucestershire, we also linked with the library service. They came to the college to enroll people and explain how they could use libraries for education, books on prescription and access to the internet etc.

We have learnt that next time we undertake to implement an improvement project we will do the following things differently:

\section{- Build in more time for planning}

- Try to find a way to robustly measure the long term cost benefit

- Understand that if the project is successful, sustainability planning needs resourcing from the start.

This quality improvement project has several key limitations:

1. It is based on a small sample of 50 students, who self selected to attend the Recovery College

2. The self reported positive outcomes have not been validated using a larger scale or longitudinal research study.

\section{Conclusion}

The results from this small scale Recovery College quality improvement project show that $94 \%$ of students felt more hopeful after attending the course. Ninety-one percent of students felt they had greater knowledge about how to self manage their condition and greater self awareness. This result is very encouraging and suggests that a wider scale research project should be undertaken to see if Recovery Colleges have the ability to support long term self management in adult mental health services.

Recovery Colleges and recovery philosophies of care represent a "disruptive innovation" to traditional mental health services and have the potential to lead to positives changes in mental health service delivery. As a source of innovation Recovery Colleges represent an opportunity to current mental health practice and services, opening up new and creative ways to making a positive difference to people's lives.

Since completing this work we secured charitable funding to continue to test, refine and develop the model and developed a suite of Recovery College courses and trained a further five peer trainers. We have continued to develop links into mainstream adult education and employment.

In Gloucestershire the service has now been commissioned to deliver an extended portfolio of courses. This was made possible because of the results we were able to demonstrate and, most importantly, because students from the course delivered several presentations to Gloucestershire Clinical Commissioning Group. Up to July 2015 approximately 300 students have attended the College and ongoing data collection confirms the positive results from the pilots. We are now collecting more data to evidence effectiveness.

We have also co-produced and developed a version of the Recovery College for younger adults (16 to 25 ) called "The Discovery College". This has been co-produced with two of the youngest graduates of the first cohort of Recovery College students. Many long term mental illnesses develop in adolescence and many graduates from the pilot Recovery Colleges expressed a wish that they had been given this form of support when they had first been diagnosed; believing that had a Recovery College been available to them, it may have changed the course of their lives. We have completed two PDSA cycles of the Discovery College to date.

Many of the original students from the three college courses described above continue to be involved in the project; either by undergoing training and coaching to become peer trainers, or by helping us to continue to improve through co-designing and contributing at events, or by helping us to disseminate the work. Many have also given us permission to share their personal qualitative testimony about how their life has changed since attending the college. This article has been co-authored, proof read and edited by students and faculty members of the Recovery College team.

\section{References}

1. World Health Organization - The Global Burden of Disease 2004 (update 2008). http://www.who.int/healthinfo/global_burden_disease/2004_r eport_update/en/

2. World Health Organization - World suicide prevention day 2012.

http://www.who.int/mediacentre/events/annual/world_suicide prevention day/en/ Accessed 16.6.2012

3. Rethink Mental IIIness. Lethal discrimination. September 2013.

4. Johnson R, Griffiths C, Nottingham T. At home? Mental health issues arising in social housing. National Institute for Mental Health in England. 2006.

5. Health and Social Care Information Centre Mental Health Bulletin: Annual Report from MHMDS Returns - England 2012/13. November 2013.

6. NICE guidelines CG123. Common mental health disorders: Identification and pathways to care. May 2011. http://www.nice.org.uk/guidance/cg123

7. Rethink Schizophrenia. http://www.rethink.org/diagnosistreatment/conditions/schizophrenia

8. NHS Choices http://www.nhs.uk/Conditions/Bipolardisorder/Pages/Introduction.aspx

9. Department of Health. Payment by Results. Draft 2012-2013 Mental Health Guidance. 2011. London.

10. Care Quality Commission, Community Mental Health Survey. 2013. 
11. Ibid

12. Mental Health Foundation. Starting Today. Final Inquiry Report. 2013 http://www.mentalhealth.org.uk/content/assets/PDF/publicati ons/starting-today.pdf?view=Standard

13. Department of Health. No Health Without Mental Health. 2011. London.

14. The Kings Fund. Paying the Price; the cost of mental health care in England to 2026. 2008.

http://www.kingsfund.org.uk/sites/files/kf/Paying-the-Price-th e-cost-of-mental-health-care-England-2026-McCrone-Dhan asiri-Patel-Knapp-Lawton-Smith-Kings-FundMay-2008 0.pdf

15. Dow KH, Ferrell BR, Haberman MR, Eaton L. The meaning of quality of life in cancer survivorship. Oncol Nurs Forum 1999 Apr;26(3):519-28.

16. Ham $\mathrm{C}$, Imison $\mathrm{C}$ et al. Where next for the NHS reforms? The case for integrated care. 2011. Kings Fund. London.

17. IMROC 'What is Recovery?' webpage www.imroc.org

18. Shepherd G, Boardman J and Burns M. Implementing Recovery: A Methodology for Organisational Change. 2011 Sainsbury Centre for Mental Health Policy Guidance. London.

19. Jacobson $\mathrm{N}$ and Greenley D. What is recovery? A conceptual model and explication. Psychiatric Services $2001 ;(52): 482-5$.

20. Cayton $\mathrm{H}$. Patient-engagement and patient decision-making in England. 2004. Paper presented at the Improving Quality of Health Care in the United States and the United Kingdom: Strategies for Change and Action.

21. Realpe A. and Wallace LM. What is Co-Production? 2010. The Health Foundation. London.

22. Department of Health. The Journey to Recovery: The Government's Vision for Mental Health Care. 2001. London.

23. American Psychiatric Association. Diagnostic and Statistical Manual of Mental Disorders, Fifth Edition. 2013. Arlington, VA: American Psychiatric Publishing.

24. Whitwell $D$. The myth of recovery from mental illness. Psychiatric Bulletin 1999;(23):621-62.

25. Coryell W and Tsuang M. Outcome after 40 year in DSM-III schizophreniform disorder. Arch Gen Psychiatr 1986;(43):324-8.

26. Harding CM, Brooks GW, Asolaga T et al. The Vermont longitudinal study of persons with severe mental illness. Methodological study sample and overall status 32 years later. Am J Psychiatr 1987;(144): 718-26.

27. Kennedy N, Abbott R and Paykel ES. Longitudinal syndrome and sub-syndromal symptoms after severe depression: 10-year follow-up study. Brit J Psychiatr 2004;(184):330-6.

28. Repper J and Perkins R. Social Inclusion and Recovery. 2003. London: Baillière Tindall.

29. Deegan G. Discovering recovery. Psychiatr Rehab J 2003;(26,suppl. 4):370

30. Resnick SG, Rosenheck RA and Lehman AF. An exploratory analysis of correlates of recovery. Psychiatr Services 2004;(55): 540-7.

31. Burhouse A. Unpublished Masters Dissertation. 2014.
Ashridge Business School, Berkhamstead, UK.

32. NICE guidelines CG136. Service user experience in adult mental health: improving the experience of care for people using adult NHS mental health services. 2011. http://www.nice.org.uk/guidance/cg136

33. Stiggelbout, AM. et al. Shared decision making: really putting patients at the centre of healthcare. BMJ 2012; 344:e256 (27th January).

34. Rinaldi M and Wybourn S. The Recovery College pilot in Merton and Sutton: Longer term individual and service outcomes. 2011. London: South West London \& St George's Mental Health NHS Trust.

35. Perkins R, Repper J, Rinaldi M and Brown H. Recovery Colleges. 2012. Briefing no. 1. from the Centre for Mental Health \& NHS Confederation Mental Health Network.

36. Davies W. Manhattan Recovery Measure. 2011.

37. Bate SP and Robert G. Bringing user experience to health care improvement: the concepts, methods and practices of experience-based design. 2007. Oxford: Radcliffe Publishing. http://www.radcliffehealth.com/shop/bringing-userexperience-healthcare-improvement- concepts-methodsand-practices-experience-based

38. Langley G, Moen R, Nolan K, Nolan T, Norman C, and Provost $\mathrm{L}$. The improvement guide: A practical guide to enhancing organizational performance (2nd ed.). 2009. San Francisco: Jossey Bass.

39. Godfrey MM, Andersson Gare B, Nelson EC, Nilsson M, Ahlstrom G. Coaching interprofessional healthcare improvement teams: The coachee, the coach and the leader perspectives. J Nurs Man 2013 DOI: 10.1111/jonm.12068.

40. Ludema JD, Wilmot TB, Srivastava S. Organizational Hope:Reaffirming the Constructive Task of Social and Organisational Inquiry. Human Relations 1997;12(50):205-7.

41. Cooperrider DL, Whitney D. Appreciative Inquiry. 1999. San Francisco: Berret-Koehler.

\section{Declaration of interests}

Nothing to declare.

\section{Acknowledgements}

We would like to thank the Health Foundation for believing in this work and granting us a Shine award. We would also like to thank the Recovery College students and experts by experience who went on this journey with us and were generous with their time and feedback. The work would not have been possible without the contribution of the peer trainers, volunteers and partner organisations who all contributed to make the Recovery College experience vibrant and memorable. A particular note of thanks to Keith Coupland and Suzie Wyld, the beating heart of the College, whose knowledge and integrity inspire us on a regular basis.

The success of this project was also founded on the advice, support and generosity of the partner organisations we worked with; Gloucestershire Adult Education Services, Herefordshire Adult 


\section{BMJ Quality Improvement Reports}

Education Services, Herefordshire MIND, Artshape and Family Lives who believed in the model and worked closely with us to deliver this service in an innovative way. Without their help and support we would not have been able to deliver this project in such an integrated way, working closely together to co-create new links and pathways.

We are also grateful to Dr Rob MacPherson, Tim Coupland, Phil Reid, Shaun Clee, Jane Melton and all other 2gether NHS staff for supporting this project and to Kate Nelmes in the Communications team for consistently going beyond what was asked of her. We would particularly like to thanks those staff in all agencies that willingly gave their own time to the project, we couldn't have done it without you. We would also like to thank Gloucestershire and Herefordshire Clinical Commissioning Groups for their ongoing support of innovation and excellence in mental health.

\section{Ethical approval}

The project was subject to Gloucestershire NHS Research and Development Committee processes and meets the required ethical standards for service evaluation. 